\title{
The Preparation of ITO nano-powder by Arc plasma method
}

\author{
Sun Lida ${ }^{1, a}$, Wang Jing ${ }^{1, b}$, Jiang Yan ${ }^{1, \mathrm{c}}$, Li Zijing ${ }^{1, \mathrm{~d}}$, Xiao Ruimin ${ }^{1, \mathrm{e}}$, Zhou \\ Shenggang ${ }^{2, *}$ \\ ${ }^{1}$ College of Science, Honghe University, Meng Zi Yunnan 661100, China; \\ ${ }^{2}$ Kunming University of Science and Technology, Kunming 650093, China \\ a sunlida0506@126.com; 'bangjing151699@163.com; \\ cjiangyan1626@126.com; 'lizijing@gmail.com; ${ }^{e x}$ rm1236@sina.com; *13888318583@126.com
}

Keywords: Arc plasma method; ITO nanopowder; Preparation

\begin{abstract}
ITO nanopowder of the high purity was prepared by self-desigred fabricated arc plasma apparatus. The crystal structure, morphology, particle size distribution and purity were characterized by X-ray diffraction(XRD), transmission electron microscopy(TEM) and Inductively Coupled Plasma Action Emission Spectrum(ICP-AES). Effects of parameters on output was studied. The results show that The results revealed that the average size of ITO powder is in the range from 30 to $80 \mathrm{~nm}$ and the purity is $99.994 \%$, powders have square crystal structures with higher dispersion and purity. This new technology can use simple process to produce high quality boron powders, and is feasible for industrial production.
\end{abstract}

\section{Introduction}

ITO nano-powder is a kind of n-type semiconductor oxide materials composed of $\mathrm{SnO}_{2}$ and $\mathrm{In}_{2} \mathrm{O}_{3}$. It has some characteristic such as low resistivity, high infrared reflectivity, and high visible light transmittance, and is widely used in high-tech fields and military fields[1][2]. China is the world's largest indium producer currently, but indium is almost exported with low-tech form of rough indium and indium ingots for lacking of deep-processing technology. High technology content and high added value products such as high indium, ITO target and indium containing semiconductor materials have not been able to form the market competitiveness, and low production, require a large number of imports from abroad. Therefore, developing the technology of ITO target is an existing target of choice for deep-processing technology and is also very urgent and necessary[3][4].ITO nano-powder is widely used for preparation of ITO film and ITO target, and it is very strict for powder used for the preparation of ITO target, such as high purity, fine grain size and uniform. Therefore, the research of ITO nano-powder is one of the hot spot in materials science. Indium as an important strategic resource reserves has been regarded and more than half of the indium has been used for the preparation of ITO materials in many developed countries such as Japan, Germany and the United States [5][6]. There are many ways for the preparation of ITO powder, such as chemical precipitation[7][8], sol-gel method [9], hydrothermal method [10], metal spray combustion method and spray pyrolysis method. In this work, ITO nano-powder was prepared by Arc plasma method which is self-developed milling equipment. This new technology can use simple process to produce high quality boron powders, and is feasible for industrial production, it provides a new way for the industrial preparation of ITO nano-powder gasification

\section{Experimental}

Preparing ITO nano-powder of device is mainly composed of a reaction chamber with an interlayer water jacket, the plasma emission and ancillary equipment, power supply and control equipment, collecting device, high pressure water cooling system. The raw materials were $\mathrm{Ar}$ (99.99\%), 4N Indium , 4N Tin and air. The plasma device was composed of a DC power of $80 \mathrm{~kW}$, thermal plasma generator with argon served as discharge gas. A tubular reactor with cooling water outside and a graphite pipe inside was closely connected to the plasma generator, Followed the 
reactor, there was a powder collector with an exhaust. Graphite crucible is connected with the anode, mixture of Indium and Tin were feed into graphite crucible by feeding equipment. The raw material is heated to melt and become metal vapor in the high temperature plasma, metal vapor reacts with oxygen to obtain the oxide particles. a large temperature gradient was formed in the water and compressed air cooling effect, metal vapor can obtain then high supersaturation region, aftet spontaneous nucleation, growth of ITO nano-particles, ITO nano-powder were obtained in the collection chamber.The apparatus used in the experiment were shown in Fig.1.

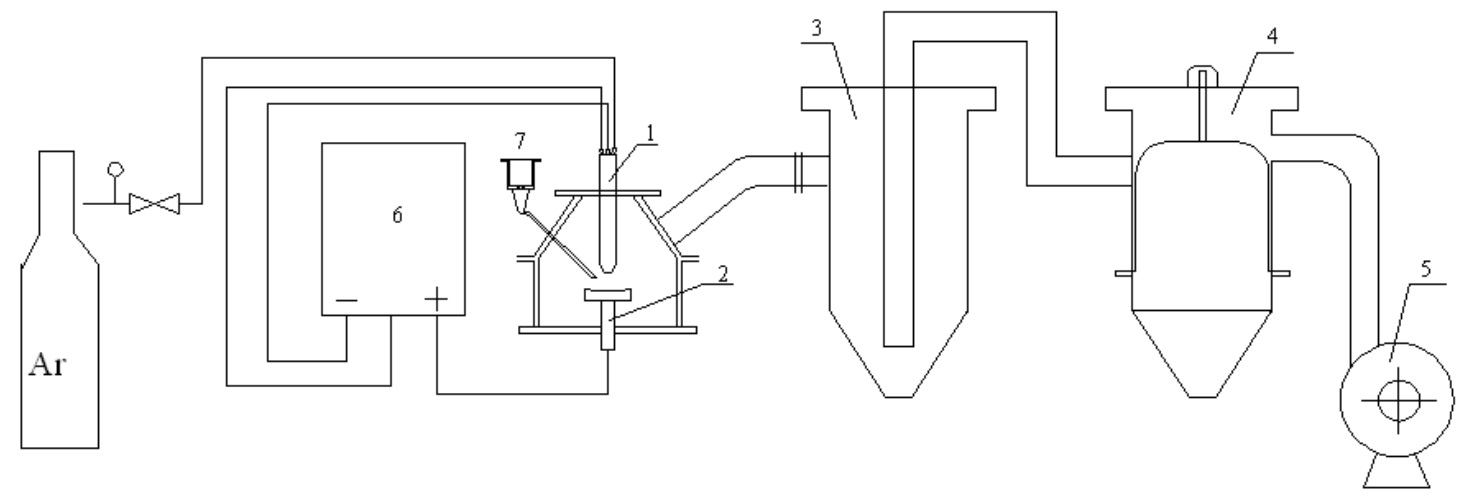

1- Plasma generator, 2-Graphite crucible, 3-Settling chamber, 4-Powders collector,

5-Exhaust fan, 6- power, 7-Feeding equipment

Fig.1 Schematic diagram of the experimental processing

The morphology and particle size of the sample were characterized by D8-AdvanceX ray diffractometer (output voltage of 220V, AXS German company), TEM420 transmission electron microscopy (accelerating voltage of $120 \mathrm{kV}$, PHILIPS Dutch company), purity were determined by Inductively Coupled Plasma Action Emission Spectrum(powder 1.0KW, Leeman Labs company of USA).

\section{Results and Discussion}

Fig. 2 shows the photos of the prepared ITO powder with TEM analysis. It can be seen that the ITO nano-powders particle with regular shape, good dispersion, uniform distribution and particle size between $30-80 \mathrm{~nm}$. The particle is four square and Characteristics of crystal structures.

In order to study the morphology and chemical composition of the prepared ITO powder, ITO powder was mixed with powder mixture (9:1) of $\mathrm{In}_{2} \mathrm{O}_{3}$ and $\mathrm{SnO}_{2}$ and was characterized by X-ray diffraction (XRD). The result is shown in Fig. 3.

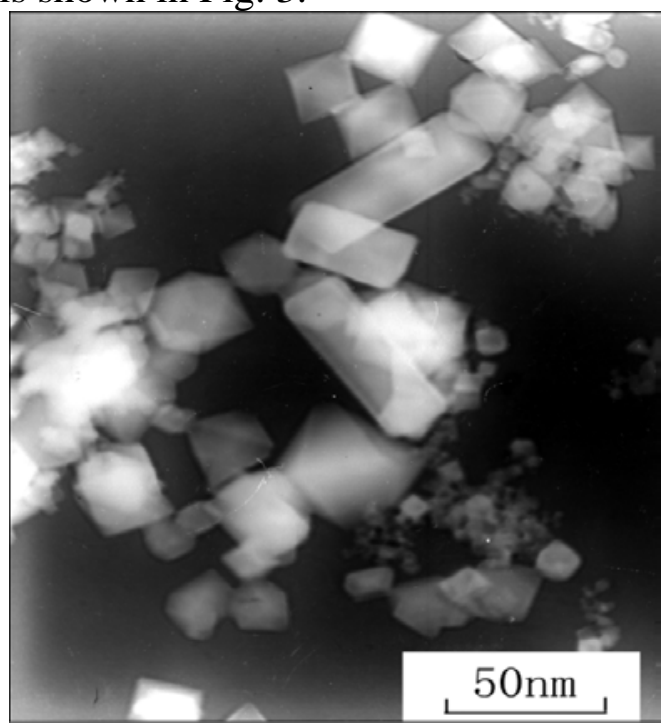

Fig.2 TEM images of the powder 


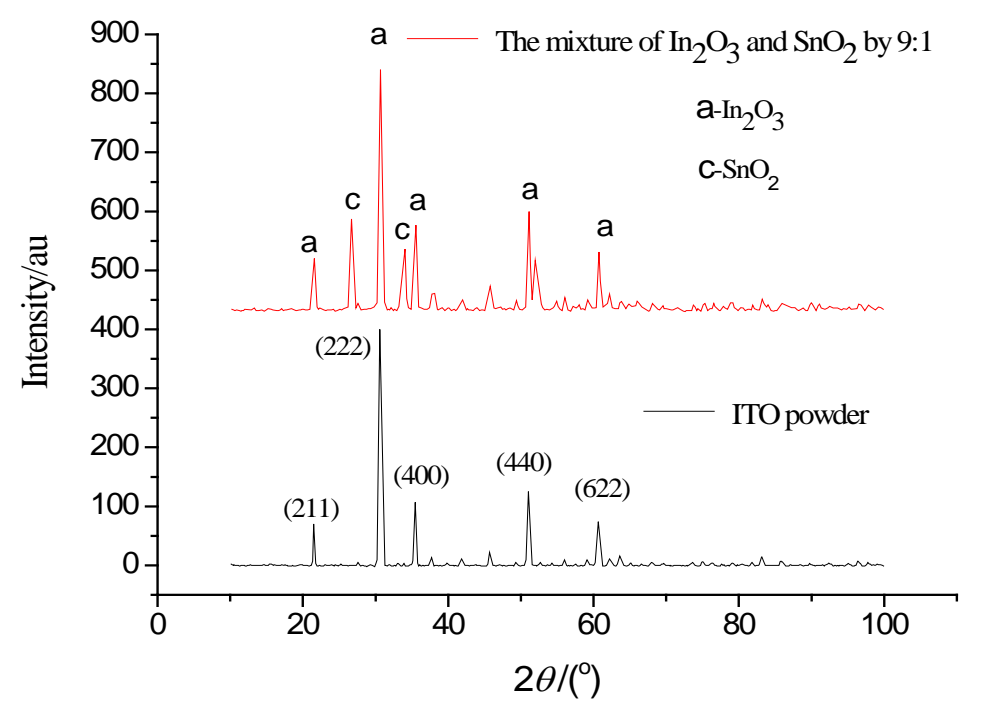

Fig.3 The XRD pattern of the powder

It can be seen from the figure that the characteristic peaks of $\operatorname{In}_{2} \mathrm{O}_{3}$ and $\mathrm{SnO}_{2}$ are all achieved in powder mixture, but no diffraction peaks of $\mathrm{SnO}_{2}$ appear in the prepared ITO powder which has five diffraction peaks within the range of $20^{\circ} \sim 80^{\circ}$. The diffraction lines of ITO nano-powder overlap with that of $\mathrm{In}_{2} \mathrm{O}_{3}$ crystal. Thus, the ITO powder is a substitution oxide solid solution with a cubic structure of $\operatorname{In}_{2} \mathrm{O}_{3}$. The tin can not form their own oxides because there are little tin in the indium oxide as $\mathrm{In}: \mathrm{Sn}=9.04: 1$ (weight ratio), and the radius of $\mathrm{In}^{3+}\left(0.81\right.$ angstroms) and $\mathrm{Sn}^{4+}(0.71$ angstroms) are similar, so that the $\mathrm{Sn}^{4+}$ be doped into indium oxide substituted part of the $\mathrm{In}^{3+}$ in the crystal lattice and formed the substitution solid solution, ITO powder [11][12]. This indium tin oxide has the same cubic structure with $\mathrm{In}_{2} \mathrm{O}_{3}$ and no new morphology structure had been formed. There is not much deviation of diffraction peak position of ITO compared with the standard pattern $\mathrm{In}_{2} \mathrm{O}_{3}$, which shows that $\mathrm{Sn}$ was doped into the crystal lattice of $\operatorname{In}_{2} \mathrm{O}_{3}$ during the heat treatment.

ITO powder is a $n$ type semiconductor high degeneracy with $\mathrm{SnO}_{2}$ and $\mathrm{In}_{2} \mathrm{O}$.The electrical properties of ITO powder will be affected affected When there are other metal elements. Some impurities will cause the target local reduction leads to target uniformity. Therefore, it's necessary for high quality ITO powder that monitor the content of impurity elements. The purity of the product was $99.994 \%$ according to the ICP-AES method, it reached the requirements. The impurity content of samples is shown in Table 1

Tab.1 Samples of impurities

\begin{tabular}{cccccccccccc}
\hline element & $\mathrm{Ca}$ & $\mathrm{Mg}$ & $\mathrm{Al}$ & $\mathrm{Fe}$ & $\mathrm{P}$ & $\mathrm{Cu}$ & $\mathrm{Si}$ & $\mathrm{Mo}$ & $\mathrm{Bi}$ & $\mathrm{Cd}$ & $\mathrm{Na}$ \\
\hline $\begin{array}{c}\text { contents } \\
\mathrm{mg} / \mathrm{kg}\end{array}$ & 4.0 & 0.5 & 0.5 & 3.4 & 0.5 & 39 & 1.0 & 0.5 & 1 & 0.1 & 0.5 \\
$\begin{array}{c}\text { element } \\
\text { contents } \\
\mathrm{mg} / \mathrm{kg}\end{array}$ & $\mathrm{Cr}$ & $\mathrm{Ni}$ & $\mathrm{Pb}$ & $\mathrm{Sb}$ & $\mathrm{Ba}$ & $\mathrm{Co}$ & $\mathrm{Mn}$ & $\mathrm{Zn}$ & $\mathrm{Sr}$ & $\mathrm{Ti}$ & $\mathrm{As}$ \\
\hline
\end{tabular}

\section{Summary}

ITO nano-powder was prepared by self-desigred fabricated arc plasma apparatus.. The particles were in the form of single particles , uniform spherical shape with particle size between 30 80nm and purity of more than $99.99 \%$.The ammonium-calcining method has great prospects for industrial applications for some advantages such as simple process, easy operation and good reproducibility. 


\section{Acknowledgement}

This work has been supported by the Chemistry of Key Construction Disciplines for Master Degree Program in Yunnan(Project No.HXY1304), the Education Department Scientific Research Foundation of Yunnan Province(Project No. 2011C118) and the project applicationfoundation of Yunnan (Project No.2013FZ123).

\section{References}

[1] X.H. Hei and W. L. Estreicher: Rare Metals and Cemented Carbides. Forum Vol.31(2003),p. 51

[2] Y.Y. Gu, L.P Qin, X.Y. Liu. Estreicher: Cent South Univ Technol . Forum Vol.13(2006):,P389

[3] W.Z Zhao . Estreicher : World Nonferrous Metal. Forum Vol. 7(2007), p. 7

[4] Y. J.Zhang, J. X.Zhang. Estreicher :Journal of Functional Materials . Forum Vol. 34(2003),p. 573-574

[5] J. Y. Zou. Estreicher : Nonferrous Metals Processing. Forum Vol. 36(2007),p.1

[6] J.X.Zhang,Z.Y.Zhang.Estreicher: Rare Metal Materials and Engineering. Forum Vol.35(2006),p. 88-90

[7] H.W. Liao. Estreicher :Nonferrous Metals. Forum Vol. 22(2006), p. 26

[8] Z. Shi, Z.K. Zhang. Estreicher: Functional Materials. Forum Vol. 28(2007),p. 289

[9] S.Z.Chen,Z.M.Yin,B.Y.Huang. Estreicher : Nonferrous Metals. Forum Vol. 52(2005),p. 88-90

[10] S.Z.Chen,L.X.Hu. Estreicher :Hunang Nonferrous Metals. Forum Vol. 52(2000),p. 88-90

[11] G.Wang,H.Y.Zhao,C.Zhao. Estreicher :Journal of Jilin University Engineering and Technology Edition. Forum Vol. 4(1994) ,p. 61

[12] M.P.Chen,Z.L.Pei,X.D.Bai.Estreicher:Chinese Journal of Material Resea .Forum Vol. 15(2005), p. 79 